\title{
PENGARUH KESELAMATAN DAN KESEHATAN KERJA TERHADAP KINERJA KARYAWAN BENGKEL RANGKUTI MOTOR UKUI PELALAWAN
}

\author{
Lamin \\ Sekolah Tinggi Ilmu Ekonomi Riau \\ E-mail: lamin@lecturer.stieriau-akbar.ac.id
}

\begin{abstract}
This study aims to determine the safety and health of employee performance. In this study data were collected through a questionnaire of 32 people. The data analysis technique used was multiple regression analysis, which serves to prove the research hypothesis. The result of testing 1 is that safety has a significant effect on employee performance seen from the t-test greater than t-table (4,414> 2,042). Test result 2 is that health has a significant effect on employee performance seen from the $t$-test greater than t-table (2,363> 2,042). The results of testing 3 safety and health have a significant effect on employee performance seen from the significance level of $0.00<0.05$. And the results of multiple linear regression shows $Y=a+b X 1+b X 2$, namely: $Y=-$ $2.340+0.623 X 1+0.317 X 2$. From the regression equation it is concluded that the regression coefficient of bx is positive. This shows that the independent variable will increase if the dependent variable increases. $R$ Square results of 0.535 (53.50\%) explained that the performance of Rangkuti Motor Ukui workshop employees was influenced by safety and health by $53.50 \%$.
\end{abstract}

Keywords: Keselamatan dan Kesehatan, Kinerja Karyawan

\section{A. PENDAHULUAN}

Salah satu faktor penting yang turut menentukan keberhasilan suatu perusahaan adalah sumber daya manusia (SDM), begitu juga dengan karyawan yang merupakan salah satu pelaku dalam menentukan dari suatu perusahaan tersebut. Karyawan harus lah benar benar mempunyai kemampuan dan keahlian di bidangnya masing masing, kemampuan karyawan dalam menanggapi masalah organisasi tersebut sangat penting. Manusia sebagai salah satu sumber daya apabila dapat digali dan dikembangkan serta ditingkatkan potensinya akan menjadi modal yang besar untuk pencapaian tujuan, tapi sebaliknya apabila diabaikan akan menjadi penghambat.

Perusahaan berkewajiban meningkatkan Keselamatan dan Kesehatan Kerja. Kewajiban perusahaan tersebut dalam meningkatkan $\mathrm{K} 3$ adalah sebagai berikut:

1. Memelihara tempat kerja yang aman dan sehat bagi pekerja.

2. Mematuhi semua standar dan syaratsyarat kerja.

3. Mencatat semua peristiwa kecelakaan yang terjadi yang berkaitan dengan keselamatandan kesehatan kerja.

Karyawan Bengkel Rangkuti Motor khususnya bagian reparasi adalah orang yang paling membutuhkam jaminan keselatan karena kondisi tempat kerja mereka yang berbahaya dan beresiko tinggi. Adanya kecelakaan merupakan masalah yang sangat merugikan pekerja dan perusahaan. Pekerja dirugikan sebab mereka mengalami kesakitan,kecacatan bahkan bisa berakibat kematian. Maka akibat dari itu, bisa menyebabkan kekacauan dalam proses projek pemasangan.

Kerugian yang disebabkan oleh kecelakaan tersebut sangatlah besar dan kemugkinan semua pihak yang terlibat baik pekerja maupun pimpinan perusahaan dan selaku kebijakan harus memahami dan menerapkan program-program tentang Keselamatan dan Kesehatan Kerja (K3) sehingga tercipta lingkungan yang aman, nyaman dan sehat. Maka demikian jumlah kecelakaan kerja dapat ditekan dan perusahaan tidak akan mengalami suatu kerugian. Maka perlu dilakukan dengan menganalisis kecelakaan kerja sehingga dapat mengurangi atau mencegah adanya kecelakaan kerja

Tabel 1: Kecelakaan Kerja Karyawan pada Bengkel Rangkuti Motor

\begin{tabular}{|c|c|c|c|c|}
\multirow{2}{*}{ Tahun } & \multicolumn{4}{|c|}{ Klasifikasi Kecelakaan } \\
\cline { 2 - 5 } & Karyawan & Luka Ringan & Luka Sedang & Luka Berat \\
\hline 2014 & 32 & 8 & 4 & - \\
\hline 2015 & 32 & 12 & 3 & - \\
\hline 2016 & 34 & 10 & 4 & - \\
\hline 2017 & 32 & 12 & 3 & - \\
\hline 2018 & 32 & 10 & 3 & - \\
\hline
\end{tabular}

Sumber : Rangkuti Motor, 2019 
Pada table 1 diatas dapat dilihat besarnya tingkat kecelakaan pada karyawan yang bekerja dengan klasifikasi kecelakaan yang paling tinggi terjadi pada tahun 2017. Standar klasifikasi disini dikelompokan menjadi 3 klasifikasi yaitu kecelakaan ringan, kecelakaan sedang, dan kecelakaan berat. Tidak dibagi berdasarkan tipe atau jenis kecelakaan tetapi dibagi berdasarkan tingkat resikonya.

Dengan demikian jelaslah bahwa kecelakaan kerja merupakan salah satu sistem dimana harus terdapat penyesuaian pekerjaan terhadap pekerjaan yang dijalankannya sehingga dapat memelihara kesehatan fisik, mental, dan kesejahtraan karyawan di semua lingkungan pekerjaan.

\section{Keselamatan Kerja}

Menurut Mangkunegara (2011:161), keselamatan kerja merupakan kondisi yang aman atau selamat dari penelitian, kerusakan atau kerugian ditempat kerja. Resiko keselamatan kerja merupakan aspek-aspek dari lingkungan kerja yang dapat menyebabkan kebakaran, ketakutan aliran listrik, perpotong, luks memsr, keseleo, patah tulang kerugian alat tubuh, penglihatan dan pandangan.

Menurut Marwansyah (2016:456) Keselamatan kerja adalah perlindungan para pekerja dari lika-luka yang diakibatkan oleh kecelakaan kerja yang berkaitan dengan pekerjaanya. Menurut Mondi dan Noe (Mutiara, 2004:112 ) Keselamatan Kerja merupakan perlindungan karyawan dari kecelakaan kerja. Sedangkan kesehatan kerja merujuk kepada kebebasan karyawan pari penyakit secara fisik maupun mental.

$$
\text { Menurut Husni (2010:136) }
$$

keselamatan kerja bertalian dengan kecelakaan yaitu kecelakaa yang terjadi ditempat kerja atau dikenal engan istilah kecelakaan industri. Kecelakaan industry ini secara umumdapat diartikan sebagai suatu kejadian yang tidak diduga semula dan dikehendaki yang mengacaukan proses yang telah diatur dari suatu aktifitas.

\section{Indikator Keselamatan Kerja}

Keselamatan adalah menunjukan kepada kondisi-kondisi fisiologis-fisikal dan psikologis tenaga kerja yang diakibatkan oleh lingkungan kerja yang di ediakan oleh perusahaan. Menurut Moenir dalam Ramdan (2014:3) indikator keselamatan kerja adalah:

a. Penempatan benda atau barang yang aman

b. Perlindungan kerja terhadap alat-alat kerja

c. Program sosialisasi petunjuk- petunjuk keamanan

d. Penyediaan perlengkapan sebagai alat pencegahan kecelakaan

\section{Kesehatan Kerja}

Menurut Husni (2010:140)

kesehatan kerja adalah bagian dari ilmu kesehatan yang bertujuan untuk agar tenaga kerja memperoleh keadaan kesehatan yang sempurna baik fisik, mental, mupun social sehingga memungkinkan dapat bekerja secara optimal. Menurut Sama'mur (2007:76) keselamatan kerja adalah spesialisasi dalam ilmu kesehatan/kedokteran beserta prakteknya yang bertujuan agar pekerja/masyarakat beserta memperoleh derajat kesehatan yang setinggi-tingginya, baik fisik, atau mental, maupun social, dengan usaha-usaha preventif dan kuratif, terhadap penyakitpenyakit/gangguan-gangguan kesehatan yang diakibatkan factor-faktornpekerjaan lingkungan kerja serta terhadap penyakitpenyakit umum.

\section{Indikator Kesehatan kerja}

Indikator kesehatan kerja menurut Manullang (2009:87) adalah:

a) Lingkungan kerja secara medis

b) Sarana kesehatan tenaga kerja

c) Pemeliharaan kesehatan tenaga kerja

\section{Kinerja Karyawan}

Penjelaskan yang dikemukakan Siswanto (2010:231) bahwa kinerja adalah kemampuan dalam melaksanakan tugasnya yang didasarkan kecakapan, usaha dan 
kesempatan. Artinya, kinerja sangat erat hubungannya dengan kemampuan seseorang dalam melaksanakan tugas.

Andreas (2009:15) mengartikan kinerja pegawai adalah hasil tingkah laku pegawai dalam melaksanakan suatu kegiatan atau pekerjaan. Pendapat ini menunjukkan bahwa kinerja pegawai berhubungan dengan sikap dan tingkah laku pegawai dalam bekerja.

Payaman (2011:2) mengartikan kinerja sebagai pencapaian hasil atas pelaksanaan tugas tertentu. Dijelaskan juga bahwa kinerja pegawai adalah tingkat pencapaian hasil kerja pegawai dalam rangka mewujudkan tujuan organisasi.

\section{Indikator Kinerja Karyawan}

Dijelaskan juga bahwa beberapa indikator yang dapat dipakai untuk mengukur kinerja karyawan menurut John Miner dalam Emron Edison (2016:195) adalah :
a. Kualitas
b. Kuantitas
c. Penggunaan Waktu
d. Kerjasama

\section{METODE}

\section{Lokasi Penelitian}

Sejalan dengan permasalahan penelitian yang telah diuraikan diatas, maka penelitian ini dilaksanakan pada Bengkel Rangkuti Motor yang beralamat di Jl. Raya Ukui, Pasar lama

\section{Populasi Dan sampel}

Populasi dalam penelitian ini adalah semua karyawan Rangkuti Motor Ukui yang berjumlah 32 orang. Dan jumlah sampel pada penelitian ini sebanyak 32 orang.

\section{Teknik Analisis Data}

Penelitian ini menggunakan Metode kuantitaif yaitu penganalisaan yang bersifat menjelaskan dan menguraikan data dan informasi yang diperoleh dengan pengukuran variabel menggunakan sakala liker's

\section{HASIL}

Analisis regresi linier berganda digunakan untuk menentukan hubungan yang linier antara variabel bebas terhadap variabel terikat, dan memprediksi variabel terikat. Berikut hasil out put SPSS :

\section{Tabel 2. Analisis Regresi Linier} Berganda Coefficients $^{a}$

\begin{tabular}{|c|c|c|c|c|c|c|}
\hline \multirow[b]{2}{*}{ Mode } & & \multicolumn{2}{|c|}{ Unstandardized Coefficients } & \multirow{2}{*}{\begin{tabular}{|c|}
$\begin{array}{c}\text { Standardized } \\
\text { Coefficients }\end{array}$ \\
Beta \\
\end{tabular}} & \multirow[b]{2}{*}{$t$} & \multirow[b]{2}{*}{ Sig. } \\
\hline & & B & Std. Error & & & \\
\hline \multirow[t]{3}{*}{1} & (Constant) & 2.340 & 6.411 & & .365 & .717 \\
\hline & keselamatan & .623 & .141 & .542 & 4.414 & .000 \\
\hline & kesehatan & .317 & .134 & .290 & 2.363 & .023 \\
\hline
\end{tabular}

\section{Sumber : Hasil Olah data SPSS}

Berdasarkan tabel diatas diperoleh persamaan regresi linier sederhana adalah sebagai berikut : $\mathrm{Y}=2.340+0,623 \mathrm{X} 1+$ $0.317 \mathrm{X} 2$

Persamaan tersebut dapat diartikan sebagai berikut :

a. Konstanta sebesar 2.340 artinya tanpa adanya keselamatan dan kesehatan, maka kinerja karyawan tetap 2.340 satuan.

b. Nilai koefisien regresi untuk variabel keselamatan sebesar 0,623 menunjukkan arah hubungan yang positif, yaitu jika variabel keselamatan meningkat satu-satuan, maka akan meningkatkan kinerja karyawan bengkel Rangkuti Motor Ukui sebesar 0,623 satuan.

c. Nilai koefesien untuk variabel kesehatan sebesar 0,317 menunjukkan arah hubungan yang positif, yaitu jika variabel kesehatan meningkat satusatuan, maka akan meningkatkan kinerja karyawan bengkel Rangkuti Motor Ukui sebesar 0,317 satuan.

\section{Uji Hepotesis Secara Parsial}

Pengujian ini digunakan untuk melihat apakah variabel independen mempunyai pengaruh yang signifikan terhadap variabel dependen dengan signifikansi 0,05 
Tabel 3: Uji_t ( Parsial )

\begin{tabular}{|c|c|c|c|c|c|c|}
\hline \multirow[b]{2}{*}{ Model } & & \multicolumn{2}{|c|}{ Unstandardized Coefficients } & \multirow{2}{*}{\begin{tabular}{|c|}
$\begin{array}{c}\text { Standardized } \\
\text { Coefficients }\end{array}$ \\
Beta \\
\end{tabular}} & \multirow[b]{2}{*}{$t$} & \multirow[b]{2}{*}{ Sig. } \\
\hline & & $B$ & Std. Error & & & \\
\hline 1 & (Constant) & 2.340 & 6.411 & & .365 & .717 \\
\hline & keselamatan & .623 & 141 & .542 & 4.414 & .000 \\
\hline & kesehatan & .317 & 134 & .290 & 2.363 & .023 \\
\hline
\end{tabular}

Sumber : Hasil Olah Data SPSS

1. Berdasarkan tabel diatas diperoleh nilai t_hitung variabel keselamatan sebesar 4,414 sedangkan untuk nilai t_tabel sebesar 2,042. maka dapat disimpulkan bahwa variabel keselamatan berpengaruh signifikan terhadap kinerja karyawan bengkel Rangkuti Motor Ukui .

2. Berdasarkan tabel diatas diperoleh nilai t_hitung variabel kesehatan sebesar 2,363 sedangkan untuk nilai t_tabel sebesar 2,042. maka dapat disimpulkan bahwa variabel kesehatan berpengaruh signifikan terhadap kinerja karyawan 3. bengkel Rangkuti Motor Ukui.

\section{Uji Hepotesis Secara Simultan ( Uji F )}

Uji simultan atau uji $\mathrm{F}$ merupakan uji secara bersama- sama untuk menguji signifikan pengaruh variabel keselamatan dan kesehatan secara bersama- sama terhadap variabel kinerja karyawan

Tabel 4. Uji_F ( Simultan ) ANOVAb

\begin{tabular}{|c|c|c|c|c|c|c|}
\hline \multicolumn{2}{|c|}{ Model } & Sum of Squares & $d f$ & Mean Square & $\mathrm{F}$ & Sig. \\
\hline \multirow[t]{3}{*}{1} & Regression & 728.744 & 2 & 364.372 & 23.548 & .000 \\
\hline & Residual & 634.415 & 41 & 15.474 & & \\
\hline & Total & 1363.159 & 43 & & & \\
\hline
\end{tabular}

a. Predictors: (Constant), kesehatan, keselamatan

b. Dependent Variable: kinerja

Sumber : Hasil Olah Data SPSS

Berdasarkan tabel diatas maka diperoleh hasil regresi berganda dari tabel di atas menunjukkan nilai Sig. Sebesar $0.000<$ 0,05 , pada tingkat kesalahan 5\%. Atau nilai F_hitung sebesar 23,548 maka dapat disimpulkan bahwa variabel keselamatan dan kesehatan secara bersama-sama mempunyai pengaruh yang signifikan terhadap variabel kinerja karyawan bengkel Rangkuti Motor Ukui .

Eko dan Bisnis (Riau Economics and Business Reviewe) Volume 10, Nomor 4, 27 Desember 2019
Koefesien determinasi ini digunakan untuk melihat kontribusi atau pengaruh yang diberikan oleh variabel bebas terhadap variabel terikat

Tabel 5. Koefesien Determinasi

\begin{tabular}{|l|r|r|r|r|}
\hline \multicolumn{5}{|c|}{ Model Summary } \\
\hline Model & \multicolumn{1}{c|}{$\mathrm{R}$} & $\mathrm{R}$ Square & \multicolumn{1}{c|}{$\begin{array}{c}\text { Adjusted R } \\
\text { Square }\end{array}$} & Std. Error of the Estimate \\
\hline 1 & $.731 \mathrm{a}$ & .535 & .512 & 3.93364 \\
\hline
\end{tabular}

a. Predictors: (Constant), kesehatan, keselamatan

Sumber : Hasil Olah Data SPSS

Berdasarkan table diatas diperoleh nilai Adjuster R Square sebesar 0,535 atau $53,50 \%$ yang memiliki arti bahwa besarnya pengaruh variabel keselamatan dan kesehatan terhadap variabel kinerja karyawan bengkel Rangkuti Motor Ukui yaitu sebesar 53,50\%.

\section{SIMPULAN}

Dari uji Anova dapat disimpulkan bahwa variabel keselamatan dan kesehatan secara bersama-sama mempunyai pengaruh yang signifikan terhadap variabel kinerja karyawan bengkel Rangkuti Motor Ukui, dari uji t dapat disimpulkan bahwa variabel keselamtan dan variabel kesehatan sacara parsial eberpengaruh signifikan terhadap kinerja karyawan bengkel Rangkuti Motor Ukui.

\section{DAFTAR RUJUKAN}

Arikunto, Suharsimi. 2010. Prosedur Penelitia., Rineka Cipta. Jakarta.

Erdison Emron, Yohny,Imas Komariyah 2016, Manajemen Sumber Daya Manusia. Bandung, Alfabeta.

Husni, 2010 Hukum Ketenaga Kerjaan.Ed.

Revisi. Jakarta:PT. Raja Grafinso

Mangkunegara, A.A. Anwar Prabu. 2011. Manajemen Sumber Daya Manusia Perusahaan. Bandung: Penerbit PT Remaja Rosdakarya

Manullang, 2009 Manajemen Personalia

Yogyakarta Gajah Mada

University Press

Marwansyah 2016, Manajemen Sumber Daya Manusia. Bandung,

Alfabeta.

P.ISSN: 1410-7988 E.ISSN: 2614-123X 
Notoatmodjo, $\quad$ Soekidjo. 2009.

Pengembangan Sumber Daya

Manusia. Rineka Cipta. Jakarta.

Panggabean, Mutiara Sibarani. 2004 Manajemen Sumber Daya Manusia. cetakan ke 2 Ghalia Indonesia", Jakarta

Ramdan, Bayu DKK. 20142013 Pengaruh Keselamatan dan Kesehatan Kerja (K3) terhadap Motivasi Kerja Karyawan Jurnal Administrasi Bisnis Vol 10 Univ. Brawijaya.

Suma'mur. 2007. Keselamatan Kerja dan Pencegahan Kecelakaan.Jakarta :Gunung Agung

Sugiyono. 2012. Metode Penelitian Bisnis. Bandung: Alfabeta

Siswanto, H. B. 2011. Pengantar Manajemen. PT. Bumi Aksara. Jakarta 